\title{
GARY BECKER'S CONTRIBUTION TO THE ECONOMICS OF MATCHING AND MARRIAGE
}

\author{
Pierre-André Chiappori \\ Columbia University, USA
}

Keywords: Becker, Matching, Transferable Utility, Complementarity

In his seminal, 1973 paper, published in the Journal of Political Economy, Gary Becker emphasizes marriage as a crucial, yet understudied issue to which economic analysis could, therefore should, be applied. In his words:

"Yet, one type of behavior has been almost completely ignored by economists, although scarce resources are used and it has been followed in some form by practically all adults in every recorded society. I refer to marriage." (p. 814)

He outlines the importance of marital patterns for understanding key economic decisions, such as labor supply, inequality, fertility and others, and concludes:

"Therefore, the neglect of marriage by economists is either a major oversight or persuasive evidence of the limited scope of economic analysis." (Ibid.)

Clearly, Becker's response follows the first path; the absence of serious, economic analysis of marriage was a regrettable oversight, that the paper intends to correct. Indeed, Becker's work played a crucial role in establishing issues linked to marriage, and more generally to family economic, at the core of economic analysis. As Pollak (2003, p. 112) puts it:

"In the competition for scarce space on the research agenda, the winners share one essential characteristic. Intrinsic interest helps, sex appeal helps, policy-relevance helps, but 'researchability' is essential. By building and analyzing simple, tractable models of family behavior, Becker demonstrated that researchability of the family".

More than forty years after the publication of Becker's paper, one can only be amazed by the success that met his bold tentative. This outcome is all the more striking when related to the explicitly hostile reaction it triggered from many fellow economists (Samuelson, talking about Becker's work on fertility, criticized “... rather sterile verbalizations [...] in terms of the jargon of indifference curves" - see Pollak 2003). Apparently, the idea that marriage could be considered from an economic perspective, although familiar to historians, sociologists or anthropologists, was something of an anathema for economists themselves. 
In retrospect, there are two main notions that were introduced by Becker, and that have since then become part of the core components of our vision of marriage. First, marital choices should be considered as explicit decisions made by rational (or at least 'intentional', to quote Boudon) individuals, and related to a general framework describing the family as an economic unit (or even as a small economy in itself, what could be called the 'household economy'). Second, both men and women compete between them for a spouse, and the outcome of these interactions can be analyzed in terms of an equilibrium. These premises have two important consequences. One is that marital sorting - who marries whom - has an important, economic component, which can be analyzed in terms of 'complementarity' or 'substitutability' of various individual traits. In particular, marriage can be assortative on some traits but not on others, depending on the impact of these traits on the household economy. The second implication is that within this economy, the allocation of resources (therefore of welfare) can be related to the equilibrium conditions prevailing on the 'marriage market'; and that the latter could profitably be analyzed using the 'theory of optimal assignments' (aka matching models), which had been introduced in economics by Koopmans and Beckman (1957) and was simultaneously developed in a more formal way by Shapley and Shubik (1971).

That these insights turned out to be crucially important for the future development of the literature is an understatement. The application of matching models to marriage patterns has recently attracted renewed interest from economists; ${ }^{1}$ invariably, these approaches follow the two key insights just described.

It is fair to say that modern approaches often depart from the exact framework used by Becker in his 1973 paper; and some features of Becker's initial contributions have been either generalized or simply abandoned. Becker's paper focuses on domestic production; in his model, individuals exclusively consume commodities that have been internally produced. Moreover, he assumes that 'all commodities can be combined into a single aggregateZ' (p. 816). Incidentally, Becker himself seems somewhat uncertain about the scope of this assumption. Indeed, he then asserts that 'our concentration on the output and distribution of $Z$ does not presuppose transferable utilities, the same preference function for different members of the same household, or other special assumptions about preferences' (ibid.). Technically, this claim is incorrect. If agents only care about the quantity they receive of the same aggregate good, then their preferences are identical - their indifference curves are just the iso-product curves of the domestic production function. And the mere fact that the respective members' shares add up to the total amount produced is exactly the definition of transferable utility (TU): the quantity of the composite good consumed by a member can always be seen as a particular cardinalization of that member's utility, and for that cardinalization the Pareto frontier is indeed a straight line with slope -1 .

We now know that the single aggregate assumption is by no means necessary. Recent contributions, starting with Lam (1988), show that a simple model in which (i) some goods are publicly consumed within the household, and (ii) utilities are 
transferable - for instance, they are of Bergstrom and Cornes (1983) 'generalized quasi linear' (GQL) form - can be analyzed as a matching model under TU, and tend moreover to generate assortative matching on income. Indeed, many recent models follow this path (see Browning et al. 2014 for a general presentation).

In particular, Becker's notion of complementarity is defined in reference to the properties of the domestic production function: individual traits are inputs to that function, and are said to be complement if (as usual) the marginal productivity of one spouse's input increase with the partner's. Modern version consider a more general concept: any TU model of household behavior generates a surplus function, which depends on both spouses' characteristics; and, in the one-dimensional case, assortative matching obtains if the surplus function is supermodular. In general, the surplus function is defined as the maximum of the sum of utilities under budget (and possibly domestic production) constraints. But neither the definition of complementarity (or supermodularity, to use the modern terminology) nor the conclusion of positive (or negative) assortative matching require commodities to be domestically produced. This is easy to see on a simple example. Assume that the household consumes two commodities, of which one, denoted $C$, is private (i.e. satisfies consumption exclusion) while the other, denoted $Q$, is publicly consumed within the household; both commodities are purchased on a market, at prices that can be normalized to one. Assume furthermore that individual only differ in income (let $y_{i}$ denotes $i$ 's income), and that preferences are Cobb-Douglas, so that utility of person $i$ is of the form

$$
u^{i}\left(C^{i}, Q\right)=C^{i} Q
$$

These preferences belong to the GQL class, so that any efficient allocation maximizes the sum of individual utilities. Define

$$
\begin{aligned}
S\left(y_{1}, \ldots, y_{n}\right)= & \max \sum_{i=1}^{n} C^{i} Q \\
& \text { under the budget constraint } \\
\sum_{i=1}^{n} C^{i}+Q= & \sum_{i=1}^{n} y_{i} .
\end{aligned}
$$

Simple algebra gives

$$
S\left(y_{1}, \ldots, y_{n}\right)=\frac{\left(\sum_{i=1}^{n} y_{i}\right)^{2}}{4} \text { therefore } \frac{\partial^{2} S}{\partial y_{i} \partial y_{j}}=1 / 2>0,
$$

and the surplus function $S$ is supermodular (equivalently, individual incomes are complement), implying that matching is assortative on income.

Another direction of generalization is the analysis of multidimensional models, in which several individual traits contribute to the surplus. Becker explicitly aims 
at considering such a multidimensional context; this is clearly stated in the abstract of the paper:

"The theory also implies that men differing in physical capital, education or intelligence (aside from their effects on wage rates), height, race, or many other traits will tend to marry women with like values of these traits..." (p. 813)

However, the notion of complementarity is harder to define in a multidimensional framework (it requires specific properties of the matrix of second cross derivatives, an issue Becker does not discuss); and, more importantly, the notion of assortative matching becomes much less obvious, precisely because of the trade-offs that appear between the various traits of any given individual. ${ }^{2}$ Again, the recent literature indicates one possible generalization, whereby complementarity (or supermodularity) is replaced with so-called 'twisted' conditions, which imply that the stable matchings are pure, in the sense that they do not involve randomization. ${ }^{3}$

Finally, Becker devotes specific attention to matching on wages. Indeed, in his core model, domestic production involves time, and individuals differ by their wage. The inescapable consequence is that matching should be negative assortative; in particular, women with university education and a high potential wage should marry low-wage husbands, who could profitably specialize in domestic production. This point is perfectly perceived by Becker ('... the correlation between mates for wage rates or for traits of men and women that are close substitutes in household production will tend to be negative.', p. 813) And it generates an interesting puzzle, since in the data the correlation between spouses' education is not only positive but remarkably stable over time, despite spectacular changes in women's education and labor supply. ${ }^{4}$ A possible solution is to consider human capital per se as an input in the domestic production function - not an unreasonable hypothesis, especially if investment in children's human capital is a major aspect of household production, as emphasized by Becker himself. But more work is obviously needed in this direction.

In summary, one can only say that, here as for many other topics, Becker's work was literally path-breaking. It opened a new direction, in which research has been active ever since; and while the technicalities of modern approaches exceed (and sometimes contradict) those of Becker's initial contribution, the basic conclusions have essentially confirmed his vision. When Becker wrote, in 1973, that:

“... theory does not take the division of output between mates as given, but rather derives it from the nature of the marriage market equilibrium". (p. 813)

he might by that time have been considered as something of a maverick. When, in retrospect, we review the evolution of family economics over the last decades, he clearly appears as a visionary. 


\section{NOTES}

1. See for instance the survey by Chiappori and Salanié (forthcoming), and the recent book by Browning et al. (2014).

2. A possible, although restrictive, solution is to refer to an 'index' approach, whereby all individual traits matter only through some one-dimensional index; see for instance Chiappori, Oreffice, and Quintana-Domeque (2012). Alternatively, one can explicitly introduce multidimensional heterogeneity in a structural, econometric framework, as in Galichon and Salanié (2012).

3. See for instance Chiappori, McCann, and Nesheim (2010) and Ekeland (2010).

4. For instance, the fraction of couples in which spouses have the same education level is roughly constant, at about 50\%, over the last four decades; see Goldin and Katz (2008) or Chiappori, Iyigun, and Weiss (2009).

\section{REFERENCES}

Becker, G. (1973) A theory of marriage: Part I. Journal of Political Economy 81, 813-846.

Becker, G. (1974) A theory of marriage: Part II. Journal of Political Economy 82, S11-S26.

Becker, G. (1991) Treatise on the Family. Cambridge, MA: Harvard University Press.

Bergstrom, T. and R. Cornes (1983) Independence of allocative efficiency from distribution in the theory of public goods. Econometrica 51, 1753-1765.

Boudon, R. (1979) La Logique du Social PUF, Paris.

Browning, M., P. A. Chiappori and Y. Weiss (2014) Economics of the Family. Cambridge, UK: Cambridge University Press.

Chiappori, P. A. and B. Salanié (forthcoming) The Econometrics of Matching Models. Journal of Economic Literature.

Chiappori, P.-A., R. McCann and L. Nesheim (2010) Hedonic price equilibria, stable matching, and optimal transport: equivalence, topology, and uniqueness. Economic Theory 42(2), 317-354

Chiappori, P. A., M. Iyigun and Y. Weiss (2009) Investment in schooling and the marriage market. American Economic Review 99, 1689-1714.

Chiappori, P. A., S. Oreffice and C. Quintana-Domeque (2012) Fatter attraction: Anthropometric and socioeconomic matching on the marriage market. Journal of Political Economy 120(4), 659-95.

Ekeland, I. (2010) Existence, uniqueness and efficiency of equilibrium in hedonic markets with multidimensional types. Economic Theory 42, 275-315

Galichon, A. and B. Salanié (2012) Cupid's invisible hand: social surplus and identification in matching models. Mimeo, Columbia University.

Goldin, C. and L. Katz (2008) The Race between Education and Technology. Cambridge, MA: Harvard University Press.

Koopmans, T. C. and M. Beckmann (1957) Assignment problems and the location of economic activities. Econometrica 25(1), 53-76

Lam, D. (1988) Marriage markets and assortative mating with household public goods: theoretical results and empirical implications. Journal of Human Resources 23(4), (fall 1988), 462-487.

Pollak, R. A. (2003) Gary Becker's contributions to family and household economics. Review of Economics of the Household 1(1), 111-141.

Shapley, L. S. and M. Shubik (1971) The assignment game I: the core. International Journal of Game Theory 1(1), 111-130. 